Article

\title{
Back to the Future: The Potential of Intergenerational Justice for the Achievement of the Sustainable Development Goals
}

\author{
Rita Vasconcellos Oliveira \\ Programme for Applied Ethics, Department of Philosophy and Religious Studies, NTNU Norwegian University \\ of Science and Technology, 7491 Trondheim, Norway; rita.bouman@ntnu.com; Tel.: +47-73596768
}

Received: 12 December 2017; Accepted: 1 February 2018; Published: 7 February 2018

\begin{abstract}
The establishment of the UN Sustainable Development Goals (SDGs) bolstered momentum to achieve a sustainable future. Undeniably, the welfare of future generations is a fundamental value of sustainable development since the publication of the Brundtland report. Nevertheless, SDGs and their targets are meagre on intergenerational justice concerns. The 15-year target horizon of the SDGs might be beneficial for implementation reasons. However, such a short-term perspective is far from innocuous in justice terms. It jeopardises the establishment of long-term goals, which protect both present and future people. This article advocates for clearer stances on intergenerational justice. What type of distributive principles could and should dictate the present socio-economic development? Looking at intragenerational justice principles contained in SDGs does not provide a full answer since they express conflicting visions of what constitutes a fair development. Furthermore, a fair distribution of the development benefits and burdens among present and near future people does not necessarily guarantee the wellbeing of more distant generations. I propose an intergenerational sufficientarian perspective as a way of extending the beneficial impacts of SDGs to both close and distant future generations. Hopefully, it facilitates the translation of the SDGs into policies that promote fairer implementation strategies.
\end{abstract}

Keywords: sustainable development goals; intergenerational justice; sufficientarianism; sustainable development; future generations; justice pluralism

\section{Introduction}

The path towards a common vision for sustainable development took a major step with the publication of the UN Sustainable Development Goals (SDGs) in 2015. In comparison to the Millennium Goals, the 17 SDGs go further in creating additional aims directly related to distributive justice.

There is a consensus that, to achieve the SDGs, policy-makers, scientists, and practitioners have to clarify how the corresponding 169 targets interconnect, analyse trade-offs and synergies, and develop metrics and models [1,2]. The need for analysis and clarification on the ethical implications of the SDGs is far less recognised. The consideration of general justice principles that are, and should be, embedded in the SDGs is yet to be fully developed. This analysis is much needed, since these principles guide the political translation of the goals and targets in concrete strategies and policies that affect us all [3,4].

So far, the reflection on the value of justice of the SDGs is mainly related to a casuistic analysis of specific goals. For example, SDGs 2: 'zero hunger' [5] and 3: 'good health and wellbeing' [2,6] have been the subject of research articles concerning justice. The limited research in this area shows the necessity of examining the general principles embodied in the SDGs and associated targets.

The focal point in this article is restricted to the intergenerational component within the wider landscape of distributive justice. The main reason for this choice resides in the nature of sustainable development. Despite different interpretations on what sustainable development is, and should 
be $[7,8]$, it is generally agreed that a desirable development for humankind is one that maintains and fosters conditions for present and future wellbeing. This stance clearly establishes the interests of future generations as a pillar of sustainable development. The centrality of future generations' interests is fully recognised in the published material by the UN [9]. Consequently, it would be expected that the SDGs substantiate the importance of future generations. However, for a variety of reasons, the majority of the SDGs are narrow in temporal scope, leading to a limited focus on future generations. Concerning future people, I claim that the SDGs focus on immediate generations, and do not ensure a fair future for more distant descendants. Moreover, there can be conflicting interests between near and distant future generations derived from short-term sustainable development policies. If the SDGs would have a longer temporal scope, generational disputes can be eased and, in some cases, even prevented. Furthermore, the adoption of an extended temporal perspective reinforces the commitment of nations to sustainable development beyond political cycles.

This article aims firstly at discussing how the lack of concrete intergenerational principles in SDGs affects their (short- and long-term) success. Secondly, there is a proposal of the reinforcement of a justice framework based on the attainment of minimal conditions, when contextualising and implementing the SDGs. Such a framework has the potential to realistically extend the benefits of goals to more distant generations than the ones covered by the SDGs.

The article is structured in the following way: it starts by analysing which generations are targeted by the SDGs. Afterwards, there is an analysis of what kind of justice principles are embodied the SDGs texts, concerning both near and distant future generations. Further on, there is a section dedicated to distributive justice and environmental reasons for the reinforcement of the intergenerational sufficientarian justice framework in the SDGs. Finally, concrete intergenerational sufficientarian sub-targets are proposed with the aim of protecting the wellbeing of near and distant future generations.

\section{The (Im)Balance in the Wellbeing of Present and Future People}

Unquestionably, SDGs try to respond to some of the most pressing problems that contemporary societies face. By redirecting development, SDGs hope to achieve better standards for people, institutions, and the environment. Like in the case of the Millennium Goals [10], SDGs are morally framed by the value of justice. More precisely, SDGs integrate statements mostly about distributive justice (theories of distributive justice support specific frameworks for dividing benefits and burdens among citizens; the justifications for such distribution are based on moral arguments that serve to guide political processes and structures [11]). SDGs set targets on how to 'better' share development costs and benefits among populations and individuals. The orientation towards distributive justice is particularly recognisable in goals such as Goal 1: 'no poverty', Goal 5: 'gender equality', or Goal 16: 'peace, justice, and strong institutions'. I further claim that justice concerns are also present in the rest of the goals via indirect pleas on distributive justice, e.g., Target 14.b aims at 'provid(ing) access for small-scale artisanal fishers to marine resources and markets', and Target 15.b requires countries to 'finance sustainable forest management and provide adequate incentives to developing countries to advance such management, including for conservation and reforestation' [12] (pp. 19-20).

It can be argued that from a justice perspective, the prime objective of the SDGs is to provide political targets that will change the course of present development so as to reach specific levels unanimously recognised as fair. Inevitably, follows the question: Who are the justice beneficiaries of these targets?

At first glance, public opinion seems to suggest that the SDGs focus on contemporary society and its individuals [13]. Looking strictly at their content reinforces this idea. There is a strong and declared commitment to the improvement of the wellbeing of the present generation, especially with regard to the worst-off, e.g., in Goal 1, Target 1.b it is written 'create sound policy frameworks ( . . ) based on pro-poor and gender-sensitive development strategies, to support accelerated investment in poverty eradication actions' $[12]$ (p. 3). 
I analysed the temporal scope of each of the 169 targets [12] and summarised the results in Figure 1. In general, the temporal frame of the SDGs extends beyond the present generation and covers its direct descendants. Approximately $48 \%$ of the SDG targets have a maximum time horizon of less than a decade and a half (2020-2030) (see Table A1). Furthermore, a considerable number of targets have no temporal scope.

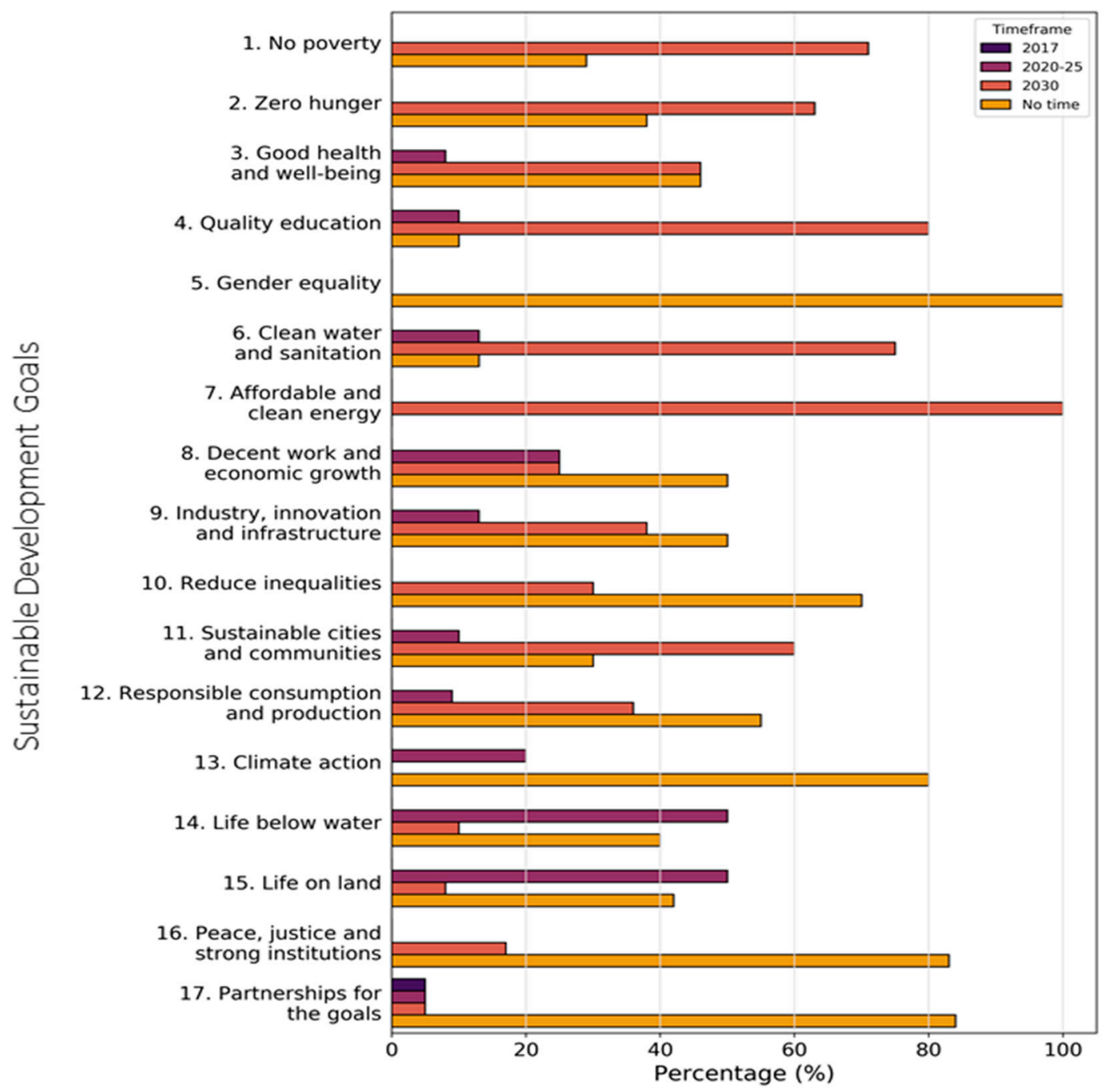

Figure 1. Temporal scale of the SDG targets by goal. The values represent the relative frequency of each specific time period, in the totality of the targets of each goal.

Interestingly, there is a less restrictive temporal agenda in the SDGs' support documentation. Expressions such as 'our common future', 'future generations', 'future challenges' [14], and 'people in the future' [15] set an open timeline for reaching the desired sustainable development level. The frequent use of these generic concepts in the SDGs' complementary and supportive documents remits the justice object to an apparent united and homogeneous group, both in time and needs. The same open timeline was already integrated into previous UN documents, such as 'Intergenerational solidarity and the needs of future generations'. In the same tone as the SDGs' support information, this report calls attention to longer time spans (hundreds of generations) as a way of acknowledging future generations beyond the 'human scale' (three generations) [16] (p. 11).

I believe that such an amalgamation blurs the goals' action landscape, and jeopardises the interests of the temporal subgroups within future generations, as I will explain further on. 
It is critical to introduce here a differentiation in generation timing to counteract this indistinctiveness. There are considerable differences in needs (the distinction between proximal and distant future generations may not be necessary when considering solely basic needs since they are largely constant through time and space) and contexts (the level of uncertainty about the physical and the socio-economic future conditions of our planet increases steeply when dealing with scenarios that are more distant in time [17]) among generations. For example, in the late XIX century, society did not need instant communication, neither was it foreseeable to need it, especially in an affordable way. Gradually, information technology became omnipresent, and now individuals expect, and many have the necessity, to communicate over large distances, from everywhere on the planet. The distant future context will surely be different from our current forecasts, due to unforeseeable natural, social, and technological changes, while the capacity to meet those needs can be severely altered due to, for example, resource availability. To capture this dichotomy, I believe it important to distinguish between the cohorts that are immediate and time wise closer to ours-here designated as proximal future generations - and the future people that are further away from our current generation—distant future generations [18].

Authors like Birnbacher [19] and Sterba [20] use similar distinctions when considering the ethical reasons for caring for the distant future (in space and time). However, the authors do not give generational or time references to what can be considered a 'distant future' or 'distant people'. Contrary to the mentioned authors, I consider that a time estimate distinguishing proximal and distant generations is beneficial when addressing sustainable development. For the sake of a systematic analysis of the generational justice principles and the implications of the SDGs, I deem it indispensable to extend and integrate the following time differentiation when analysing the UN's future development trends. In this article, I define proximal future generations as the cohort of individuals belonging up to a second generation (roughly between $40-55$ years) [21], while the people born after this second generation compose distant future generations.

Using the above distinction, I claim that the SDGs' desideratum should be to foster fair socio-ecological conditions beyond the present and proximal future generations. General claims on the establishment of a better future without concrete long-term intentions and actions will not ensure fairness for distant future generations. It is critical to understand that fair(er) present and proximal future conditions will not automatically ensure a fair distant future. There are two main reasons for such a claim.

First, the non-homogeneity of needs within future generations is bound to create tensions between different temporal cohorts. This means that setting principles and courses of action meant to favour justice towards proximal future generations might conflict with the establishment of principles and actions towards people from a distant future. The main motive for this is an increasing distinctiveness of eco-socio-economic settings as the timeframe extends.

A justice dilemma is presented to illustrate the diversity increment of future scenarios with timespan, and the potential conflict between the interests of cohorts. The dilemmatic situation relates to the consensual fair targets of Goal 7. This goal aims at providing affordable and clean energy to all people by 2030. The achievement of Goal 7 requires the increase in the production and use of renewable energies, especially in Asia and sub-Saharan Africa. Independently of the specific energy source(s) chosen to meet this goal [22-24], the criteria for any option vary according to the chosen timeframe. To achieve energy fairness for proximal future generations, the type of clean energy production structures must be operational in just a few years, and should not require unaffordable initial investments. The variables to consider while guaranteeing energy fairness for distant future generations are of another kind. A fair option should be the one with least future impacts (e.g., costs), while ensuring functionality in diverse future scenarios.

Indisputably, the production of solar energy is one of the favourite options for generating 'clean and affordable' energy, especially in low-density population areas like sub-Saharan Africa. Since 'by 2030, (we should) increase substantially the share of renewable energy in the global energy mix' [12] 
(p. 10), investments in these technologies are to be considered fair actions. However, studies indicate relevant (health and environment) toxicity burdens in the production of solar PV, which will mainly impact distant future generations. The situation will be further aggravated by technology upscaling. Recent research findings point to significant effects in an extensive production growth scenario [25]. Simply put, actions meant to increase energy fairness ought to account for lock-in effect [26] and potential adverse consequences for distant future generations of some of the technological possibilities. In line with this argument, and using a similar example, Kermisch and Taebi established a framework for evaluating nuclear energy that has the interests of close and distant (remote) generations at its centre. By doing so, the authors argue it affects the very notion of sustainability [27].

Another reason for distinctly addressing the wellbeing of proximal and distant future generations, in the context of SDGs, relates to responsibility and agency. Both present and proximal future generations determine the possibility of a fair development for (proximal and distant) future generations. In that sense, they are both responsible for future conditions. However, only proximal future generations are foreseeable agents of the future. Since present generations cannot fully foresee or determine (at least, all) proximal future generations' actions, the SDGs' moral framework must give latitude to proximal future generations for them to adapt to future scenarios, without compromising the interests of distant future people.

As they are written today, SDGs and their targets leave the door open to social and environmental injustice for (distant) future generations. They do not acknowledge and respond to ascertainable potential contradictions in principles and actions taken to ensure the wellbeing of those future people. All in all, the core ambition of sustainable development is to meet the needs of the present without compromising future generations to meet their own needs [28], and, by extension, SDGs are not accomplishable without the inclusion of (some) longer-term targets.

\section{The Distributive Justice Principles in the SDGs}

Societies have a determined social background in which the partition of economic, environmental, and cultural benefits among citizens is differentiated. Such differences are a product of socio-economic and ethical frameworks, which change over time and across societies. Like with many other ethical problems, the answer to what is the correct way to share these benefits and burdens varies. The different positions about morally-preferable frameworks and/or resulting distributions lead to differentiated practical societal scenarios. These differences demand consideration and reflection when devising policies for a more sustainable future.

As mentioned before, the SDGs aim at transforming the current eco-socio-economic landscape into a future with a fairer division of benefits and burdens. To make clear the different stances on justice concerning future generations, I analysed the SDGs for distributive justice principles behind the concrete developmental objectives. I orient and benchmark this examination against the theoretical claims of the distributive justice theories.

The examination was narrowed down to the documents that specifically enunciate the goals [29,30], leaving out the supporting literature and documentation, since the signing countries did not officially endorse them. Each of the 17 SDGs is individually contextualised and justified in three sections ('progress and info 2016', 'progress and info 2017', and 'targets and indicators'), which form the documental basis of my investigation. I narrowed the focus to the final list of proposed SDG targets and indicators [12] and performed a textual analysis for all 169 targets in search of (intraand intergenerational) distributive justice principles that affect present and future generations.

The distributive justice principles were categorised into three classes, according to the theoretical criteria of sufficientarianism [31,32], egalitarianism [32,33], and prioritarianism (prioritarianism belongs to the family of egalitarian theories; however, it was individualized from the general equalitarianism, since it focuses primarily on the worst-off instead of the general population) $[33,34]$. To classify a target as being part of a class, certain keywords, concepts, and phrases distinctive to each class had to be present in the target's text [12]. In the case of target descriptions without clear 
distributive justice claims, it was classified as without justice statement (see Table A2). Table 1 shows the corresponding classification of key concepts for each distributive justice theory. Table A3 provides a more detailed overview of the textual analysis.

Table 1. Correspondence between key concepts and distributive justice theories.

\begin{tabular}{cr}
\hline Justice Theory & Concepts \\
\hline Egalitarianism & Universal; equality; inclusiveness; global justice \\
Prioritarianism & Specific population groups; Specific communities, businesses, or countries \\
Sufficientarianism & Explicit thresholds; increases or reductions of parameters \\
\hline
\end{tabular}

The SDGs' targets were classified according to the concepts and keywords correspondent to the three different distributive justice classes. However, in the case of multiple concepts present in a single target, the target is counted as having a double (or triple) classification. Subsequently, the absolute count of classes for all targets with justice statements was normalised, and these relative results are presented in Table A2. Figure 2 plots the SDGs in the egalitarian-prioritarian-sufficientarian triangle. Their position is based on the average position of the associated targets reflecting egalitarian, prioritarian, or sufficientarian justice frameworks. The size of the circles corresponds to the relative amount of targets in which a justice position is incorporated, i.e., the smaller the circle, the more targets have no justice positioning. Figure 2 shows that the distribution of justice claims among SDG targets is not homogeneous. Eighty percent of the analysed targets have some form of justice statement. In these targets, intergenerational egalitarian and prioritarian views are predominant, covering, respectively, $46 \%$ and $43 \%$. Intergenerational sufficientarian principles are far less common and represent only $11 \%$ of targets, as represented in Figure 2.

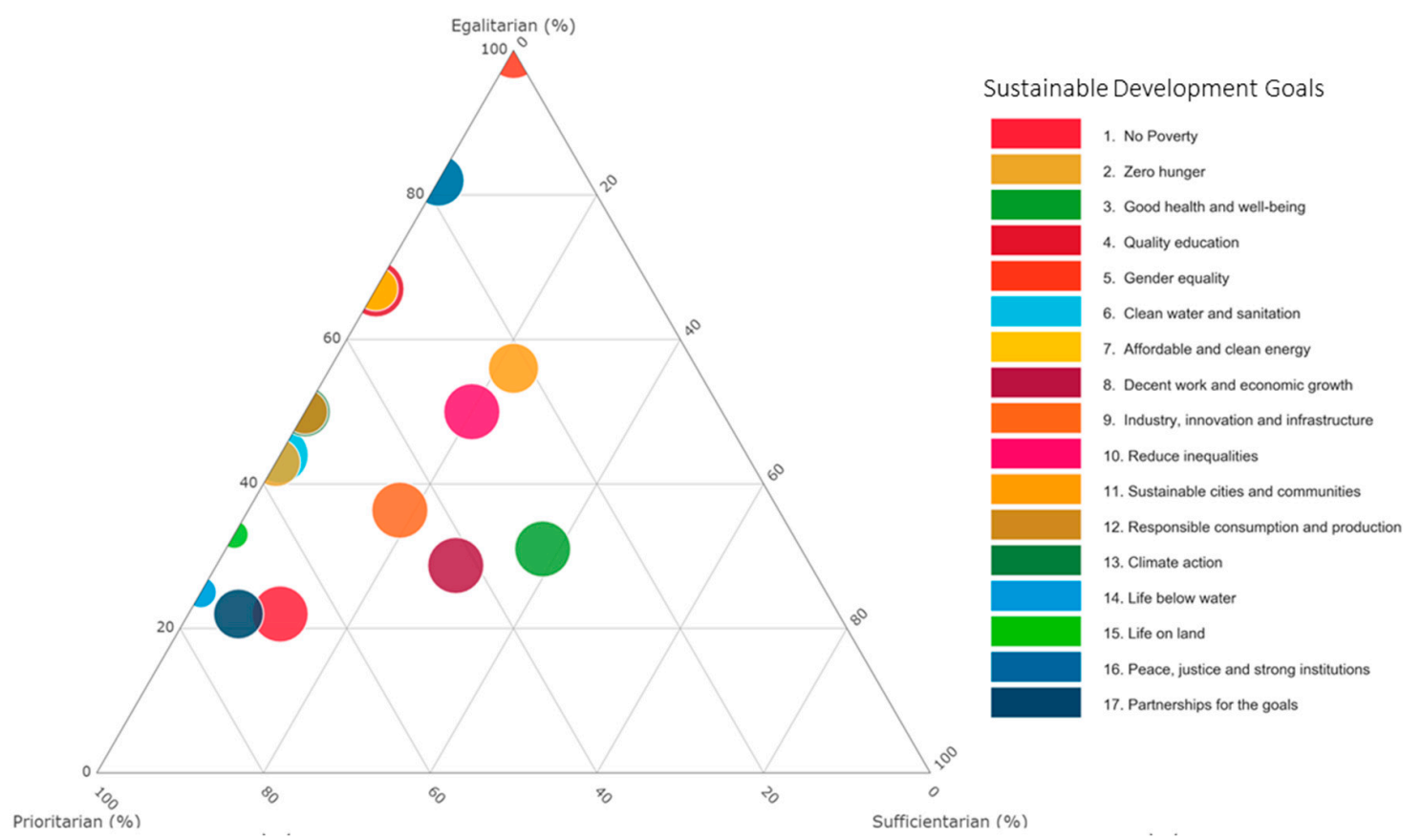

Figure 2. Results from the textual analysis on the SDGs targets which contained (intra- and intergenerational) distributive justice statements. Each of the targets was benchmarked against the principles of equalitarianism, prioritarianism, and sufficientarianism. The results are grouped by goal (for detailed information, see Table A2).

Figure 2 shows a predominance of egalitarianism (egalitarianism is the distributive justice theory that states that societal burdens and benefits (e.g., wealth, income) should be divided equally among 
all citizens. This falls on the postulate that all human beings are equal in worth and in moral status. When egalitarianism is applied to future generations, the result is the obligation of distributing equally the burdens and benefits among present and future people [35]) in subjects like peace, justice and institutions (Goal 16), and in quality and education (Goal 4). In these topics, the SDGs aim at distributing more evenly the benefits of development. Equalizing rights and redistributing resources more evenly is so relevant in the SDGs that the UN dedicated a goal to promote gender equality (Goal 5). Furthermore, there are strong appeals to egalitarianism in every other goal, e.g., in Goal 10, countries are urged to reduce 'inequalities in income' [12] (p. 13) (for detailed information, see Table A2).

Prioritarianism (prioritarianism favours welfare for the worst-off people. It is very relevant for this justice view, the different levels of the welfare that individuals have in an overall wellbeing scale: the worse off a person is, the greater importance his or her improvement of wellbeing has [36]) is another relevant and constant distributive justice framework in the SDGs. All goals include statements about giving precedence to the worst-off ('in particular the poor and the vulnerable') [12] when establishing concrete actions to diminish inequality. The preponderance of prioritarianism happens in developmental topics connected to aquatic resources (Goal 14), partnership for achieving the goals (Goal 17), poverty (Goal 1), and land resources (Goal 15). Not surprisingly, there are individual SDG targets that incorporate both egalitarian and prioritarian justice frameworks (for detailed information, see Table A2).

The sufficientarian principles of justice (sufficientarianism is a theory of distributive justice that is neither concerned with inequalities, nor with making the situation of the least well-off as good as possible. The objective of sufficientarian justice is to ensure that each individual has enough. In an intergenerational context, sufficientarianism requires that present generations leave enough resources for the future people insofar that they will have minimal life conditions [37]) are not prevalent in the SDGs, as shown in Figure 2. The SDGs infused with such justice have a focus on human development, which benefits individuals below certain wellbeing thresholds. The goal on health (Goal 3) exemplifies the moral priority of bettering the wellbeing of those who fall below a minimum of health coverage quality, namely in maternal and new-born health (Targets 3.1 and 3.2). The improvement of working conditions below decency is also another relevant sufficientarian target (Goal 8) (for detailed information, see Table A2).

In general, the results show a common ideal of sustainable development, which nurtures a future with less social and environmental inequality. The analysis also reveals a more diversified vision on distributive justice parameters in some particular issues (see Figure 2). The SDGs' core texts transmit the notion that, in particular cases, it is not enough to guarantee all citizens equal access to resources and opportunities, but rather ensure basic conditions for all people. There is a kind of 'justice pluralism' in the sense of an agreement in adopting contrasting general justice principles concerning the problem of mitigating distribution inequality $[38,39]$. The mix of justice principles in the SDGs opens space for devising implementation strategies, which ensure that present, proximal, and distant generations achieve a developmental state where these conditions are met.

\section{A Fair Future for All Generations: Integrating Sufficientarianism in the SDGs}

As discussed previously, sustainable development targets can only be considered true to the cause of sustainability if they integrate measures that ensure distributive justice to both proximal and distant generations. Consequently, SDGs should incorporate general justice principles that safeguard a fair allocation of benefits and burdens among all generations to come.

As discussed in the previous sections, SDGs adopt a 'pluralistic' distributive justice frame for present and proximal future generations, but miss out on the wellbeing of distant future people. This situation creates the opportunity of proposing the integration of distant future generations' interests, in the SDGs implementation strategies. Such integration can be translated in the development of sub-targets (e.g., national, regional) for proximal and distant future generations and/or the introduction of intergenerational sufficientarian sub-targets when assessing the implementation actions. The main 
aim here is a more systematic consideration and application of intergenerational sufficientarian principles in the sustainable development strategies.

\subsection{The Cause of Future Sufficiency}

To make a case for intergenerational sufficientarianism for future generations, it is fundamental to understand the main characteristics and implications of this justice theory. Sufficientarianism, in an intergenerational context, dictates that the measure of fairness is the wellbeing of future people in relation to a certain threshold. Strictly speaking, the distribution of benefits and burdens among generations must be such that all cohorts reach minimum life standards [33]. Present generations have the duty to create the conditions so that no future individual falls below the sufficient level. Contrary to the intuition of many, intergenerational sufficientarians think that an equal distribution of benefits and burdens among cohorts is not, per se, a just allocation. The level of (in)equality among individuals of different generations is of no importance for intergenerational sufficientarians [31-33]. Their concern is that every individual attains a minimum standard of wellbeing (from a theoretical perspective, 'classical' sufficientarianism is compatible and combinable with other intergenerational justice perspectives such as egalitarianism. Sufficientarian principles are very similar to some forms of egalitarianism such as the up-limit leximin egalitarianism and the utilitarian aggregative perspective on wellbeing/welfare. Up-limit leximin egalitarianism and prioritarian perspectives are non-individualistic. The prime objective of both is set on total wellbeing [40]), as shown in Figure 3.
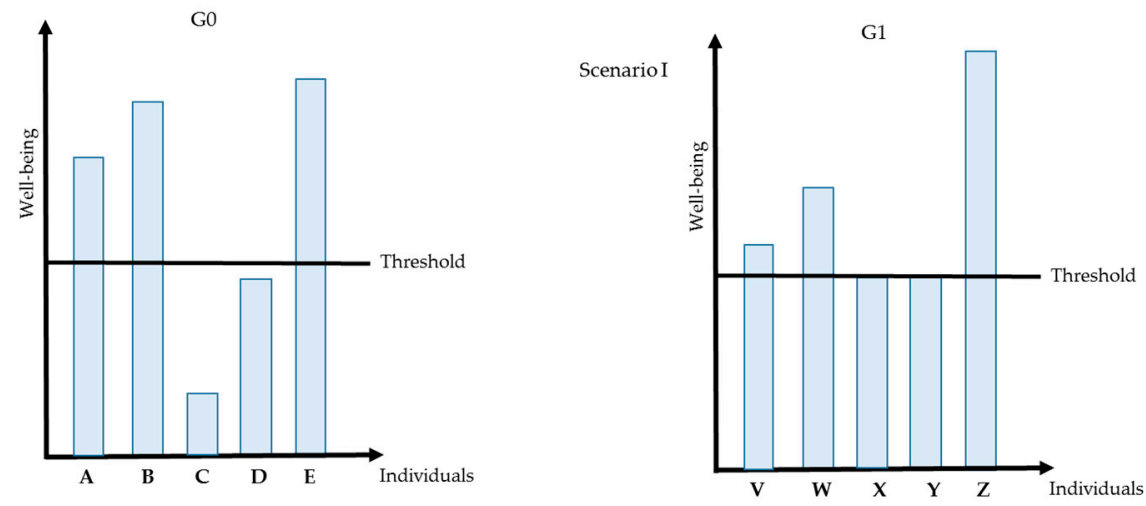

a)

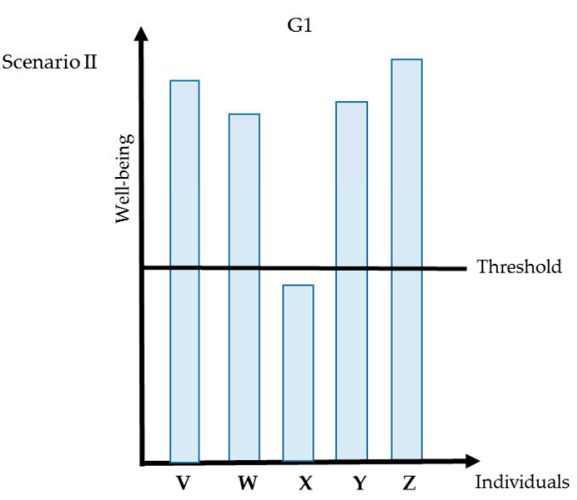

b)

Figure 3. Examples of fictitious wellbeing distributions between two generations. (a) Wellbeing distribution in the initial generation; (b) Two potential wellbeing distributions in the following generation. Scenario I follows sufficientarianism, while scenario II follows egalitarian and prioritarian distributive justice principles. 
Figure 3 shows a hypothetical example of wellbeing distribution among generations. In this example, the present generation, or generation zero (G0), is composed of five individuals with different levels of wellbeing. For the sake of simplicity, it is assumed that the generation after G0 (G1) has the same size as the previous one. For the same reason, it is assumed that there are only two possible distributive justice possibilities: scenario I and II. According to intergenerational sufficientarianism, only scenario I is fair. Despite scenario II having more aggregated wellbeing and less inequality, it is not a just future because individual $\mathrm{X}$ has not reached the minimum threshold of wellbeing. Intergenerational sufficientarianism requires all G1 individuals to have minimum standards of wellbeing.

In a nutshell, for intergenerational sufficientarians, one must support a present human development that ensures all people, at any future time, have at least minimal levels of wellbeing.

\subsection{Reinforcing Intergenerational Wellbeing beyond the Near Future}

It is not enough to promote equal sharing of eco-socio-economic resources and burdens, within the present and near-future generations to guarantee that future people enjoy desirable living conditions. Wellbeing equality among generations might compromise the necessary ecological balance, especially with growing demographics [41].

In light of this, I propose the strengthening of intergenerational sufficientarian distributive justice standards in the context of the SDGs. The reinforcement of sufficientarian justice principles in policies targeting future development is also necessary for the following reason: in comparison to other distributive justice theories, especially egalitarianism, sufficientarianism is particularly useful and favourable in a general intergenerational context [31,34,42]. In response, some authors try to offer potential distributive justice approaches that overcome the intrinsic and extrinsic value limitations of intergenerational egalitarianism. For example, Beckman [43] suggests a 'humanistic' framework based on the priority of creating a decent society for future generations. However, this proposal reduces sustainability to a social dimension, relegating the environmental aspects to the mere background. Environmental studies have repeatedly demonstrated this to be a dangerous path [17].

Without exploring in detail the theoretical reasons for such appropriateness, it is relevant to mention that intergenerational sufficientarianism has the particular potential to foster sustainability and sustainable development [44]. Gardiner and Shue are examples of authors that sustain the opinion that individuals are entitled to carbon emissions necessary for some minimum level of wellbeing [45]. Other works of Shue reinforce the notion of sufficiency as specific sufficient conditions, with regard to human wellbeing, that will necessarily trigger political action to protect (future) people [46].

Most importantly, intergenerational sufficientarianism does not fall into the trap of an intangible and unreasonable equality of unsustainable life conditions (e.g., consumerism) but, on the contrary, advocates for a minimal (or reasonable) wellbeing.

I go further in supporting intergenerational sufficientarianism and defend its improved adequacy in the specific context of the SDGs. Intergenerational sufficientarianism responds far better to the uncertainty of future scenarios (distant future generations) and regional eco-socio-economic specificities because it allows differentiated threshold(s) of wellbeing.

In addition, intergenerational sufficientarianism stands for the individual wellbeing, within each generation, instead of focusing on the impersonal 'aggregated good', as in intergenerational egalitarianism and prioritarianism. The value of each person's wellbeing is not lost in group definitions (e.g., 'worst-off') or in agglomerates of natural and social goods, which may or may not be decisive for human wellbeing (intergenerational egalitarianism).

Another merit of this theory is the facilitated translation of its justice principles in sustainable development criteria, i.e., it is not particularly challenging to apply this theory to concrete SDGs' strategies. Additionally, it is possible to transform its axioms to practical parameters to include in the assessment of the SDGs targets (see Appendix B). 
It is relatively straightforward to introduce and articulate minimum thresholds when contextualising (e.g., temporally, geographically) the majority of the SDGs targets. According to the nature of the SDGs and respective targets, minimum levels can be set as sub-targets. These levels can be quantitative (e.g., above $\$ 1.25$ ) or qualitative (e.g., basic services). Such minimal thresholds can be determined for both proximal and distant future generations (see Tables A4 and A5).

Tables A4 and A5 illustrate the possibility of reinforcing present generations' and future generations' wellbeing within the SDGs framework. The tables show sub-targets for SDGs 1: 'no poverty' and 7: 'affordable and clean energy' as examples of how SDGs can grant intergenerational distributive justice based on intergenerational sufficientarianism while preserving the wellbeing of present, proximal, and distant future generations. The proposed sub-targets can be part of (global and regional) implementation strategies for the achievement of the SDGs. In line with the justice frame of intergenerational sufficientarianism, one can find, in Tables A4 and A5, keywords such as minimal, minimum, and basic, as well as quantitative values (e.g., 95\%, triple), which reflect sufficientarian thresholds.

As shown in Table 2, for example, the suggestion (for Sub-target 1.3) is that all individuals, firstly below minimum conditions, and afterwards below world-average living conditions, would be covered by social protection.

Table 2. Proposed intergenerational sufficientarian Sub-target 3, for Goal 1: end poverty.

\begin{tabular}{ccc}
\hline Sub-Goal & Present, First, and Second Generations & After the Second Generation \\
\hline \multirow{3}{*}{1.3} & By 2055, implement nationally appropriate social & After 2055, implement nationally appropriate \\
protection systems and measures so to cover all & social protection systems and measures so to \\
people living in what is and will be internationally & cover increasingly more people below \\
agreed as below minimum conditions. & world-average living conditions. \\
\hline
\end{tabular}

The integration and reinforcement of intergenerational sufficientarianism in the SDGs sub-targets will not generally change the intent of the original texts. However, in the case of sub-target 7.1 (see Tables 3 and A5), the purpose is to grant 'affordable, reliable, and modern energy services' [12] (p. 10), while what is proposed here is to guarantee that those energy services are provided to people at minimum cost. In this case, there might be a scenario when the cost of sustainable energy might still be too high for people living below certain living standards. However, there are social mechanisms (e.g., subsidies) that can ensure that non-universally affordable energy can be available to individuals with less economic power.

Table 3. Proposed intergenerational sufficientarian Sub-target 1, for Goal 7: affordable and clean energy.

\begin{tabular}{ccc}
\hline Sub-Goal & Present, First, and Second Generations & After the Second Generation \\
\hline 7.1 & $\begin{array}{c}\text { By 2055, ensure access to reliable and } \\
\text { sustainable energy services at minimum cost. }\end{array}$ & $\begin{array}{c}\text { After 2055, continue the strategies that } \\
\text { ensure access to reliable and sustainable } \\
\text { energy services at minimum cost. }\end{array}$ \\
\hline
\end{tabular}

It is important to notice that threshold values used in Tables 2 and 3 and Tables A4 and A5 are solely indicative. Such values can set by social, scientific, and/or political agreement.

The suggested sub-targets have the added benefit of using the same indicators, or similar measures to the ones already defined, in UN documents. Overall, indicators would not change considerably, despite the changes in the targets' distributive and temporal justice frames.

These frameworks affect the level or value considered to be adequate (just), the targeted population (individuals below minimum conditions), and how long it is necessary to monitor a particular phenomenon (covering both present, proximal, and distant future generations). For example, in Goal 7: 'affordable and clean energy', Target 7.3 translates into the indicator 'energy intensity measured in terms of primary energy and GDP' [12] (p. 10). According to the suggestions, the indicator 
would be the same. The change would occur in the analysis of the target. The objective would be attained when, in the first stage, energy efficiency would triple, and afterwards, if this efficiency would continue increasing until the practical maximum (see Table A5).

The implementation of intergenerational sufficientarianism for protecting and enhancing distant future generations' wellbeing can, de facto, facilitate decision- and strategy-making for sustainable development. Again, using Goal 7 as an example, a longer temporal framework (6-8 generations: 120-160 years) gives better guidance to what 'clean energy' and 'fuels' actually mean (see Table A5, Sub-targets 7.2 and 7a). In the case of decision-making based on environmental assessment tools, it is necessary to understand what timeline to consider when dealing with trade-offs between potential environmental impacts. As previously mentioned, in the case of energy technology, long-term environmental effects can be better managed with a plausible and justified quantitative notion of time.

Another advantage to the reinforcement of intergenerational sufficientarianism is the (possible) setting of evolving thresholds. As exemplified in Table A4, the poverty reduction targets (Goal 1) were established at the level of minimal and basic living conditions, for present and proximal future generations. Nevertheless, the aim for distant future generations is set higher: at world average. It can be argued that establishing evolving thresholds creates a positive direction for sustainable development while accommodating world socio-economic dynamics. The establishment of multiple thresholds can happen within a generation. As Widerquist writes, it is possible to establish lower and upper wellbeing thresholds so that society pursues the improvement of the worst-off people without disregarding the advancement of the ones that are better off [47].

An intergenerational sufficientarianism justice structure allows world targets and differentiated subsets of thresholds according to national and regional characteristics. The adoption of subsets of 'situational thresholds' has the added benefit of being a concrete answer to differentiated eco-socio-economic conditions, especially derived from past national rates of human development. Environmental and historical factors (e.g., colonialism, racial tensions, and natural disasters) affect not only present eco-socio-economic conditions, but also influence the conditions for future development. Through the implementation of 'situational thresholds', present and future individuals who live in areas where basic standards are higher than most poor regions, and yet do not reach the desired minimum wellbeing, are made morally eligible to benefit from additional help. As illustrated in Goal 1, Table A4, it is plausible and fairer to use such a differentiation strategy, because there are, at present, considerable national, regional, and local disparities in the vulnerability to poverty, which affect the present and future capacity of response.

The setting of global and regional baselines for wellbeing (e.g., poverty reduction) conveys the notion of moral obligation towards the elimination of the worst poverty circumstances in absolute terms. Additionally, it obliges us to improve localised and particular conditions that affect individuals below regional levels of minimal living conditions, in relative terms. For example, it seems undeniable that poor people in Daca and New York need help to better their living situation, even if only the Bangladeshi destitute are below easily-recognisable minimal wellbeing situations.

Despite the positive aspects, the reinforcement of intergenerational sufficientarianism in the SDG discourse and praxis would not come without challenges. Presumably, the most difficult one would be the establishment and acceptance of 'basic' and 'minimum' standards. This requirement would trigger additional international discussion among nations' representatives and stakeholders. The positive aspect of a common reflection on fundamental conditions for any human being is the opportunity for increased societal engagement and reflection on concrete conditions for a fair future.

\section{Conclusions}

The SDGs are a timely opportunity for present generations to adopt a socio-economic development that guarantees the wellbeing of future people. Despite the unanimous acknowledgment of the relevance of fair distribution principles in the implementation of sustainable development strategies, distant future generations' requirements are not minimally ensured by the current formulation of the 
SDGs. The short timeline of the SDGs mainly promotes a more equal division of very minimal goods (e.g., education, maternal health) among genders and countries of origin. Despite these flaws, the SDGs' agreement can still promote a steady increase in distributive justice for proximal and distant future people.

A mapping of the SDGs to three distributive justice frameworks shows that most SDGs reflect egalitarian and prioritarian principles. Since the objective is to increase distributive justice for current, proximal, and distant future generations, additional sub-targets are proposed and based on the principals of intergenerational sufficientarianism. SDGs 1: 'no poverty' and 7: 'affordable and clean energy' were used as examples of how targets can be specifically formulated under such principals. In general, the aim is to set (at least) two thresholds for each SDG target, corresponding to the two generational timeframes (until and after 2050). More importantly, the level of the proposed thresholds rises in time to guarantee that no individual falls below those lower limits, while ensuring a continuous growth in the overall wellbeing.

It is expected that including intergenerational sufficientarian principles, in the form of the suggested sub-targets, harmonises the longer developmental timeframe with the obligation of taking present action to safeguard sufficient wellbeing conditions for all present and future people.

Acknowledgments: This study was funded by the programme for applied ethics of the Norwegian University of Science and Technology. I thank Evert Bouman, from the Norwegian Institute for Air Research, for the design of the figures, and the anonymous reviewers for their valuable comments and suggestions.

Conflicts of Interest: The author declares no conflict of interest.

\section{Appendix A}

Table A1 shows the distribution by goal of the temporal scale of the each UN SDG target.

Table A1. Results of the timeframe analysis of the SDGs targets.

\begin{tabular}{|c|c|c|c|c|c|}
\hline & Goal & $2017(\%)^{1}$ & $2020-2025(\%)^{1}$ & $2030(\%)^{1}$ & No Time $(\%)^{1}$ \\
\hline 1 & No Poverty & - & - & 71 & 29 \\
\hline 2 & Zero hunger & - & - & 63 & 38 \\
\hline 3 & Good health and wellbeing & - & 8 & 46 & 46 \\
\hline 4 & Quality education & - & 10 & 80 & 10 \\
\hline 5 & Gender equality & - & - & - & 100 \\
\hline 6 & Clean water and sanitation & - & 13 & 75 & 13 \\
\hline 7 & Affordable and clean energy & - & - & 100 & - \\
\hline 8 & Decent work and economic growth & - & 25 & 25 & 50 \\
\hline 9 & Industry, innovation and infrastructure & - & 13 & 38 & 50 \\
\hline 10 & Reduce inequalities & - & - & 30 & 70 \\
\hline 11 & Sustainable cities and communities & - & 10 & 60 & 30 \\
\hline 12 & Responsible consumption and production & - & 9 & 36 & 55 \\
\hline 13 & Climate action & - & 20 & - & 80 \\
\hline 14 & Life below water & - & 50 & 10 & 40 \\
\hline 15 & Life on land & - & 50 & 8 & 42 \\
\hline 16 & Peace, justice and strong institutions & - & - & 17 & 83 \\
\hline \multirow[t]{2}{*}{17} & Partnerships for the goals & 5 & 5 & 5 & 84 \\
\hline & Totals & 1 & 13 & 35 & 51 \\
\hline
\end{tabular}

\footnotetext{
${ }^{1}$ The table values represent the relative frequency of each specific time period, in the totality of the targets of each goal.
} 
Table A2. Summarises the results of the textual analysis regarding the relative amount of targets that include or not distributive justice principles. It accounts for both intra- and intergenerational statements.

\begin{tabular}{|c|c|c|c|c|c|}
\hline & & Egalitarian $^{1}$ & Prioritarian $^{1}$ & Sufficientarian $^{1}$ & No Justice $^{2}$ \\
\hline & Goals & $(\%)$ & $(\%)$ & $(\%)$ & Statement $(\%)$ \\
\hline 1 & No poverty & 22 & 67 & 11 & - \\
\hline 2 & Zero hunger & 43 & 57 & - & 25 \\
\hline 3 & Good health and wellbeing & 31 & 31 & 38 & - \\
\hline 4 & Quality education & 67 & 33 & - & - \\
\hline 5 & Gender equality & 100 & - & - & - \\
\hline 6 & Clean water and sanitation & 44 & 56 & - & - \\
\hline 7 & Affordable and clean energy & 67 & 33 & - & 40 \\
\hline 8 & Decent work and economic growth & 29 & 43 & 29 & - \\
\hline 9 & Industry, innovation and infrastructure & 36 & 45 & 18 & - \\
\hline 10 & Reduce inequalities & 50 & 30 & 20 & - \\
\hline 11 & Sustainable cities and communities & 56 & 22 & 22 & 20 \\
\hline 12 & Responsible consumption and production & 50 & 50 & - & 36 \\
\hline 13 & Climate action & 50 & 50 & - & 20 \\
\hline 14 & Life below water & 25 & 75 & - & 70 \\
\hline 15 & Life on land & 33 & 67 & - & 75 \\
\hline 16 & Peace, justice and strong institutions & 82 & 18 & - & 17 \\
\hline \multirow[t]{2}{*}{17} & Partnerships for the goals & 22 & 72 & 6 & 21 \\
\hline & Totals & 46 & 43 & 11 & 20 \\
\hline
\end{tabular}

${ }^{1}$ The initial sample of targets of each goal was sub-divided in two groups: targets with and without justice statements. The values represent the relative frequency of each specific distributive justice framework, in the group of targets with justice statements. ${ }^{2}$ The values represent the relative frequency of the group of targets without justice statements based on the totality of targets that concern each goal.

Table A3 shows the coding used to classify the 169 SDGs targets present in the list of Sustainable Development Goal indicators [12] into distributive justice theory classes.

Table A3. Detailed correspondence between keywords and concepts to distributive justice theories with examples taken from the SDGs targets.

\begin{tabular}{|c|c|c|c|}
\hline Justice Theory & Keywords & Concepts & Examples in Target Statements \\
\hline Egalitarianism & $\begin{array}{l}\text { All; equal(ity); equitable; } \\
\text { universal; full; inclusive, } \\
\text { people everywhere }\end{array}$ & $\begin{array}{l}\text { Universal (access/coverage); } \\
\text { prevent all forms of } \\
\text { discrimination/environmental } \\
\text { impacts (e.g., acidification); full and } \\
\text { effective participation; global justice, } \\
\text { reinforcement of international law }\end{array}$ & $\begin{array}{l}\text { 'Prevent trade restrictions and } \\
\text { distortions' (2.b); 'enhance } \\
\text { international cooperation' (7.a); } \\
\text { 'non-discriminatory' (16.b) }\end{array}$ \\
\hline
\end{tabular}

\section{Appendix B}

Tables A4 and A5 provide examples of intergenerational sufficientarian sub-targets that address present and future generations' proximal and distant wellbeing. For simplicity, only two goals (SDGs 1: 'no poverty' and 7: 'affordable and clean energy') were chosen as exemplificative samples of how SDGs can grant intergenerational distributive justice based on intergenerational sufficientarianism, to present, proximal, and distant future generations.

The proposed sub-targets were based on the SDGs text so as to portray, as accurately as possible, the intentions of the signatory countries. 
Table A4. Proposed intergenerational sufficientarian sub-targets for Goal 1: 'no poverty', targeting present, proximal, and distant future generations.

\begin{tabular}{|c|c|c|}
\hline $\begin{array}{c}\text { Intergenerational } \\
\text { Sufficientarian Sub-Targets }\end{array}$ & Present, First, and Second Generations & After the Second Generation \\
\hline 1 & $\begin{array}{c}\text { By 2030, eradicate extreme poverty for } \\
\text { people currently measured as people living } \\
\text { on less than } \$ 1.25 \text {. } \\
\text { From } 2030 \text { onwards, maintain and, if necessary, } \\
\text { reinforce the eco-socio-economic strategies that } \\
\text { prevent people from falling into extreme poverty. }\end{array}$ & $\begin{array}{l}\text { From } 2030 \text { onwards, maintain and if necessary, reinforce } \\
\text { the eco-socio-economic strategies that prevent people } \\
\text { from falling into extreme poverty. }\end{array}$ \\
\hline 2 & $\begin{array}{c}\text { Between } 2015 \text { and 2055, steadily reduce, at least } \\
\text { by half, the proportion of people living below, } \\
\text { what is internationally agreed as being } \\
\text { minimum wellbeing conditions. }\end{array}$ & $\begin{array}{l}\text { After 2055, steadily reduce the proportion of people } \\
\text { living below world-average living conditions. }\end{array}$ \\
\hline 3 & $\begin{array}{l}\text { By } 2055 \text {, implement nationally appropriate social } \\
\text { protection systems and measures so to cover all } \\
\text { people living what is and will be internationally } \\
\text { agreed as below minimum conditions. }\end{array}$ & $\begin{array}{l}\text { After 2055, implement nationally appropriate social } \\
\text { protection systems and measures so to cover increasingly } \\
\text { more people below world-average living conditions. }\end{array}$ \\
\hline 4 & $\begin{array}{l}\text { By 2055, ensure that all people have access to } \\
\text { basic services, partial ownership and control over } \\
\text { land and other forms of property, inheritance, } \\
\text { basic rights to economic, natural and technological } \\
\text { resources and financial services, } \\
\text { including microfinance. }\end{array}$ & $\begin{array}{l}\text { After 2055, ensure that increasingly more people have } \\
\text { access to good quality services, more ownership and more } \\
\text { control over land and other forms of property, } \\
\text { inheritance, rights to economic, natural and } \\
\text { technological resources and financial services, } \\
\text { including microfinance. }\end{array}$ \\
\hline 5 & $\begin{array}{l}\text { By 2055, build the resilience of those living below } \\
\text { minimal conditions and reduce, at least } 40 \% \text { their } \\
\text { exposure and vulnerability to climate-related } \\
\text { extreme events and other economic, social and } \\
\text { environmental shocks and disasters. }\end{array}$ & $\begin{array}{l}\text { After 2055, build the resilience of those living below or at } \\
\text { world-average conditions and reduce, each decade, at least } \\
30 \% \text {, their exposure and vulnerability to climate-related } \\
\text { extreme events and other economic, social and } \\
\text { environmental shocks and disasters. }\end{array}$ \\
\hline a & $\begin{array}{l}\text { By } 2055 \text {, ensure a } 30 \% \text { increase in the mobilisation } \\
\text { of resources from a variety of sources, including } \\
\text { through enhanced development cooperation, to } \\
\text { provide adequate and predictable means to } \\
\text { implement programmes and policies to end } \\
\text { living conditions below minimal standards. }\end{array}$ & $\begin{array}{l}\text { After 2055, ensure a steady increase in the mobilisation } \\
\text { of resources from a variety of sources, including through } \\
\text { enhanced development cooperation, to provide adequate } \\
\text { and predictable means to implement programmes and } \\
\text { policies to end living conditions } \\
\text { below world average standards. }\end{array}$ \\
\hline b & $\begin{array}{l}\text { By } 2055, \text { create sound policy frameworks at the } \\
\text { national, regional and international levels, } \\
\text { to eradicate poverty, measured as less than } 60 \% \\
\text { of the average national salary. }\end{array}$ & $\begin{array}{l}\text { After 2055, ensure the application of policy frameworks } \\
\text { at the national, regional and international levels, to } \\
\text { prevent the re-incidence of poverty, based on based on the } \\
\text { future measures of poverty. }\end{array}$ \\
\hline
\end{tabular}

Table A5. Proposed intergenerational sufficientarian sub-targets for Goal 7: 'affordable and clean energy', targeting present, proximal, and distant future generations.

\begin{tabular}{|c|c|c|}
\hline $\begin{array}{c}\text { Intergenerational } \\
\text { Sufficientarian Sub-Targets }\end{array}$ & Present, First, and Second Generations & After the Second Generation \\
\hline 1 & $\begin{array}{l}\text { By 2055, ensure access to reliable and sustainable } \\
\text { energy services at minimum cost. }\end{array}$ & $\begin{array}{c}\text { After 2055, continue the strategies that ensure } \\
\text { access to reliable and sustainable energy services } \\
\text { at minimum cost. }\end{array}$ \\
\hline 2 & $\begin{array}{l}\text { By 2055, increase no less than } 95 \% \text { the share of } \\
\text { renewable energy in the global energy mix } \\
\text { guaranteeing minimum adverse effects for the } \\
\text { environment and humans, in the short term (40 years). }\end{array}$ & $\begin{array}{l}\text { After 2055, continue to increase the share of } \\
\text { renewable energy in the global energy mix } \\
\text { guaranteeing minimum adverse effects for the } \\
\text { environment and humans in the short (40 years) } \\
\text { and long term (minimum of } 120-160 \text { years). }\end{array}$ \\
\hline 3 & $\begin{array}{l}\text { By 2055, at least triple the global rate of improvement } \\
\text { in energy efficiency. }\end{array}$ & $\begin{array}{l}\text { After 2055, continue to improve the global rate of } \\
\text { improvement in energy efficiency until it reaches } \\
\text { the practical maximum. }\end{array}$ \\
\hline a & $\begin{array}{l}\text { By } 2055 \text {, increase at least } 60 \% \text { international } \\
\text { cooperation to facilitate access to clean energy } \\
\text { research and technology, including renewable energy, } \\
\text { energy efficiency and advanced and cleaner fossil-fuel } \\
\text { technology, and promote investment in energy } \\
\text { infrastructure and clean energy technology that } \\
\text { guarantees minimum adverse effects for the } \\
\text { environment and for humans in the short } \\
\text { term ( } 40 \text { years). }\end{array}$ & $\begin{array}{l}\text { After 2055, ensure a steady increase in } \\
\text { international cooperation to facilitate access to } \\
\text { clean energy research and technology, including } \\
\text { renewable energy, energy efficiency and } \\
\text { advanced and cleaner fossil-fuel technology, } \\
\text { and promote investment in energy infrastructure } \\
\text { and clean energy technology that guarantees } \\
\text { minimum adverse effects for the environment } \\
\text { and for humans, in the short- (40 years) and } \\
\text { long-term (minimum of } 120-160 \text { years). }\end{array}$ \\
\hline $\mathrm{b}$ & $\begin{array}{l}\text { By 2055, expand infrastructure and upgrade } \\
\text { technology for supplying modern and sustainable } \\
\text { energy services for countries below average } \\
\text { development including small island states and } \\
\text { landlocked developing countries, in accordance with } \\
\text { national and international programmes of support. }\end{array}$ & $\begin{array}{l}\text { After 2055, ensure that countries have access and } \\
\text { deploy the best available sustainable energy } \\
\text { services in accordance with national and } \\
\text { international programmes of support. }\end{array}$ \\
\hline
\end{tabular}




\section{References}

1. Costanza, R.; Fioramonti, L.; Kubiszewski, I. The UN Sustainable Development Goals and the dynamics of wellbeing. Front. Ecol. Environ. 2016, 14, 59. [CrossRef]

2. Waage, J.; Yap, C.; Bell, S.; Levy, C.; Mace, G.; Pegram, T.; Unterhalter, E.; Dasandi, N.; Hudson, D.; Kock, R. Governing the UN sustainable development goals: Interactions, infrastructures, and institutions. Lancet Glob. Health 2015, 3, e251-e252. [CrossRef]

3. Carter, N. The Politics of the Environment: Ideas, Activism, Policy; Cambridge University Press: Cambridge, UK, 2001; ISBN 0521469945.

4. Gutmann, A.; Thompson, D. Moral Conflict and Political Consensus. Ethics 1990, 101, 64-88. [CrossRef]

5. Hawkes, C.; Popkin, B.M. Can the sustainable development goals reduce the burden of nutrition-related non-communicable diseases without truly addressing major food system reforms? BMC Med. 2015, 13, 143. [CrossRef] [PubMed]

6. Tangcharoensathien, V.; Mills, A.; Palu, T. Accelerating health equity: The key role of universal health coverage in the Sustainable Development Goals. BMC Med. 2015, 13, 101. [CrossRef] [PubMed]

7. Kates, R.W.; Parris, T.M.; Leiserowitz, A.A. What is sustainable development? Goals, indicators, values, and practice. Environment 2005, 47, 8-21.

8. Diesendorf, M. Sustainability and sustainable development. In Sustainability: The Corporate Challenge of the 21st Century; Dunphy, D., Benveniste, J., Griffiths, A., Sutton, P., Eds.; Allen \& Unwin: Sydney, Australia, 2000; Volume 2, pp. 19-37. ISBN 9781865082288.

9. United Nations (UN). The future we want. In Proceedings of the A/RES/66/288 United Nations Conference on Sustainable Development, Rio+20, Rio de Janeiro, Brazil, 20-22 June 2012; Report of the United Nations Conference on Sustainable Development, U.N. Doc. A/CONF.215/16 (28 September 2012). UN: New York, NY, USA, 2012; pp. 1-53.

10. Kabeer, N. Can the MDGs Provide a Pathway to Social Justice? The Challenges of Intersecting Inequalities; UN MDG Achievement Fund and Institute of Development Studies: New York, NY, USA, 2010.

11. Roemer, J.E. Theories of Distributive Justice; Harvard University Press: Cambridge, UK, 1998; ISBN 0674879201.

12. United Nations (UN). Final List of Proposed Sustainable Development Goal Indicators. In Report of the Inter-Agency and Expert Group on Sustainable Development Goal Indicators; United Nations Economic and Social Council, Statistical Commission; Document E/CN.3/2016/2/Rev. 1; UN: New York, NY, USA, 2017. Available online: https:// sustainabledevelopment.un.org/content/documents/11803Official-Listof-Proposed-SDG-Indicators.pdf (accessed on 17 October 2017).

13. Giannini, R.; Muggah, R. The New Sustainable Development Goals Advocate for Peace and Justice. Is Brazil Listening? Available online: https:/ / www.opendemocracy.net/democraciaabierta/robert-muggah-renaragiannini/new-sustainable-development-goals-advocate-for-peace (accessed on 8 November 2017).

14. United Nations (UN). The future we want. In Proceedings of the A/RES/66/288 United Nations Conference on Sustainable Development, Rio+20; Rio de Janeiro, Brazil, 20-22 June 2012, Report of the United Nations Conference on Sustainable Development, U.N. Doc. A/CONF.215/16 (28 September 2012); UN: New York, NY, USA, 2012; p. 53.

15. Brundtland Commission. Our Common Future. Chapter 2: Towards sustainable development. In World Commission on Environment and Development (WCED); United Nations: Geneva, Switzerland, 1987.

16. United Nations (UN). General Assembly Intergenerational Solidarity and Needs of Future Generations-Report of the Secretary General; U.N. Doc. A/68/X (5 August 2013); UN: New York, NY, USA, 2013.

17. Rickards, L.; Ison, R.; Fünfgeld, H.; Wiseman, J. Opening and closing the future: Climate change, adaptation, and scenario planning. Environ. Plan. C 2014, 32, 587-602. [CrossRef]

18. Posner, E.A. Agencies should ignore distant-future generations. Univ. Chic. Law Rev. 2007, 74, 139-143.

19. Birnbacher, D. What motivates us to care for the distant future. In Proceedings of the Séminaire Développement Durable et Économie de L'environnement, Organisé par l'IDDRI et la Chaire Développement Durable de l'Ecole Polytechnique, France, Paris, 21 February 2006; Institut du Développement Durable et des Relations Internationales: Paris, France, 2006.

20. Sterba, J.P. The welfare rights of distant peoples and future generations: Moral side-constraints on social policy. Soc. Theory Pract. 1981, 7, 99-119. [CrossRef]

21. ISOGG. Generation Length. Available online: https://isogg.org/wiki/Generation_length\#Average_ generation_length (accessed on 15 November 2017). 
22. Demirtas, O. Evaluating the best renewable energy technology for sustainable energy planning. Int. J. Energy Econ. Policy 2013, 3, 23.

23. Armaroli, N.; Balzani, V. The future of energy supply: Challenges and opportunities. Angew. Chem. Int. Ed. 2007, 46, 52-66. [CrossRef] [PubMed]

24. Chu, S.; Majumdar, A. Opportunities and challenges for a sustainable energy future. Nature 2012, 488, 294. [CrossRef] [PubMed]

25. Alonso, E.; Sherman, A.M.; Wallington, T.J.; Everson, M.P.; Field, F.R.; Roth, R.; Kirchain, R.E. Evaluating rare earth element availability: A case with revolutionary demand from clean technologies. Environ. Sci. Technol. 2012, 46, 3406-3414. [CrossRef] [PubMed]

26. Perkins, R. Technological “Lock-In”. In Encyclopaedia of Ecological Economics. Neumayer, E., Ed.; 2003. Available online: http:/ / isecoeco.org/pdf/techlkin.pdf (accessed on 11 December 2017).

27. Kermisch, C.; Taebi, B. Sustainability, Ethics and Nuclear Energy: Escaping the Dichotomy. Sustainability 2017, 9, 446. [CrossRef]

28. Brundtland, G.H. Our common future-Call for action. Environ. Conserv. 1987, 14, 291-294. [CrossRef]

29. UN Economic and Social Council. Progress towards the Sustainable Development Goals, Report of the Secretary_General on Sustainable Development; U.N. Doc. E/2017/66 (28 July 2016-27 July 2017); UN: New York, NY, USA, 2017.

30. UN Economic and Social Council. Progress towards the Sustainable Development Goals, Report of the Secretary -General on Sustainable Development; U.N. Doc. E/2016/75 (24 July 2015-27 July 2016); UN: New York, NY, USA, 2016.

31. Page, E.A. Justice between generations: Investigating a sufficientarian approach. J. Glob. Ethics 2007, 3, 3-20. [CrossRef]

32. Gosseries, A. Qu'est-ce que le suffisantisme? Philosophiques 2011, 38, 465-491. [CrossRef]

33. Gosseries, A. Theories of intergenerational justice: A synopsis. SAPI EN. S. Surv. Perspect. Integr. Environ. Soc. 2008, 1, 61-71. [CrossRef]

34. Gosseries, A.; Meyer, L.H. Intergenerational Justice; Oxford University Press: Oxford, UK, 2009.

35. Pojman, L.P.; Westmoreland, R. (Eds.) Equality: Selected Readings; Oxford University Press: New York, NY, USA, 1997; ISBN 9780195102505.

36. Arneson, R.J. Luck egalitarianism and prioritarianism. Ethics 2000, 110, 339-349. [CrossRef]

37. Shields, L. The prospects for sufficientarianism. Utilitas 2012, 24, 101-117. [CrossRef]

38. Walzer, M. Spheres of Justice: A Defense of Pluralism and Equality; Basic Books: New York, NY, USA, 2008.

39. Schlosberg, D. Environmental Justice and the New Pluralism: The Challenge of Difference for Environmentalism; Oxford University Press: Oxford, UK, 1999.

40. Meyer, L.H.; Roser, D. Enough for the future. In Intergenerational Justice; Gosseries, A., Meyer, L., Eds.; Oxford University Press: Oxford, UK, 2009; pp. 273-300.

41. Barry, B. Sustainability and intergenerational justice. In Fairness and Futurity: Essays on Environmental Sustainability and Social Justice; Dobsons, A., Ed.; Oxford University Press: Oxford, UK, 1999; pp. $93-117$.

42. Gosseries, A. Intergenerational justice, sufficiency, and health. In Sufficiency, Justice, and Health-What Is Enough? Fourie, C., Rid, A., Eds.; Oxford University Press: New York, NY, USA, 2016; pp. 121-143.

43. Beckerman, W. Sustainable development and our obligations to future generations. In Fairness and Futurity: Essays on Environmental Sustainability and Social Justice; Dobsons, A., Ed.; Oxford University Press: Oxford, UK, 1999; pp. 71-92.

44. Vasconcellos Oliveira, R.; Thorseth, M. Justice with a future: Contributions from sustainability to intergenerational sufficientarianism. De Ethica 2018. under review.

45. Gardiner, S.M. Ethics and climate change: An introduction. Wiley Interdiscip. Rev. Clim. Chang. 2010, 1, 54-66. [CrossRef]

46. Shue, H. Deadly Delays, Saving Opportunities. Creating a more dangerous World. In Climate Ethics: Essential Readings; Gardiner, S., Ed.; Oxford University: Oxford, UK, 2010; pp. 146-162. ISBN 9780195399622.

47. Widerquist, K. How the sufficiency minimum becomes a social maximum. Utilitas 2010, 22, 474-480. [CrossRef] 